\title{
A Comparison of Two Controller Designs for a Hybrid Excitation Synchronous Generator for Wind Applications
}

\author{
Sandrine Le Ballois and Lionel Vido \\ SATIE, ENS Cachan, CNRS, Cergy Pontoise University \\ 5, mail Gay Lussac, Neuville sur Oise, 95031 Cergy Pontoise, France \\ Phone/Fax number: +33/134256900, e-mail: sandrine.leballois@u-cergy.fr, lionel.vido@u-cergy.fr
}

\begin{abstract}
The purpose of this paper is to establish a robust and low-cost structure for a generator connected to an isolated load for wind applications. In a hybrid excitation synchronous generator (HESG), the excitation flux is created by both permanent magnets and excitation coils, so the output voltage can be controlled by the DC excitation field. For isolated loads, it is then possible to use a simple and very reliable wind generator architecture, composed only by a HESG, a rectifier and a DC/DC converter to control the excitation flux. However, HESM are non-linear machines so, regarding their control, conventional controllers are not always sufficient to ensure a good stability and high performance. In this paper, a comparison between a PI controller and an $\mathrm{H}_{\infty}$ controller is investigated. The comparison examines both performance and robustness to parameters' uncertainty.
\end{abstract}

\section{Key words}

Wind Turbine, HESG, Robust Control, $\mathrm{H}_{\infty}$ Control, PI Control

\section{Introduction}

Everybody knows that global warming is a growing threat to the environment and scientists are more than $90 \%$ certain that this phenomenon is primarily due to increasing concentrations of greenhouse gases produced by human activities such as the burning of fossil fuels. It is now absolutely necessary to reverse the global warming trend and to reduce levels of greenhouse gases emissions into the atmosphere. An obvious way is to use renewable energies. Among these, wind technology has demonstrated its effectiveness as a low carbon supplier and wind energy is currently the fastest-growing source of electricity in the world with an average global growth rate of $29 \%$ per year since 1990. The potential for wind power is substantial. Today, wind could contribute up to $2.5 \%$ of global electricity demand. To enhance the share of wind power in the global power supply, it is vital to make the price of wind power competitive with conventional means of electricity generation. The purpose of this paper is to establish a low-cost structure for a wind generator connected to an isolated load.

Today wind generators are mainly of two types [1]: synchronous [2], [3] and induction machines [4], [5]. Even if there is little consensus on the best architecture for the future wind generator systems, it seems that the trend of the wind energy production goes to synchronous machines. Synchronous machines are either permanent magnets
(PMs) machines or wound rotor synchronous machines. Using PMs instead of a DC field winding in the rotor allows significant advantages such as a higher efficiency due to the absence of rotor copper loss, a higher power density due to the elimination of DC field winding and a faster response due to the lower electromechanical time constant of the rotor. Because of the high prices of rare earth magnets and because the main purpose of this paper is to establish a low-cost structure, the studied machine uses ferrite permanent magnets. Moreover, make use of a hybrid excitation synchronous generator (HESG) can further reduce the cost. Indeed, in HESG, excitation flux is created by both permanent magnets and excitation coils, so the output voltage can be controlled by the DC excitation field. For isolated loads, it is then possible to use a simple and very reliable wind generator architecture, composed only by a HESG, a rectifier and a DC/DC converter to control the excitation flux [6][7][8].

In [9], L.Vido et al. studied four prototypes of HESM and showed that a bipolar hybrid excitation allows a better control than a homopolar configuration. In [10], Y. Amara et al. presented a study of control laws adapted to so-called "double excitation" or "hybrid" structures... In this paper, this original machine is studied for a wind turbine application showing how the excitation coils can be a degree of freedom to control the generator. However, regarding the control scheme, a HESM has significant drawbacks compared to other types of generators. First of all, HESM are strongly non-linear machines. Developing accurate non-linear models is difficult so classical assumptions are made: magnetic saturation is not considered since the machine operates in the linear mode, only a first harmonic model is considered and, at last, iron and mechanics losses are neglected. It is a very common practice to neglect these complex phenomena since it is difficult to take them into account in a dynamic model. Furthermore, due to the difficulty to properly identify the machine parameters, one can consider that most of these are very uncertain.

Fortunately, these drawbacks can be overcome by adapting control methods. In this study, a cascade control scheme is adopted, with an inner current loop and an outer velocity loop. In both cases, a simple PI controller is implemented for the inner loop since the current model is linear. Then a comparison between an adaptive PI controller and an $\mathrm{H}_{\infty}$ controller is investigated for the 
velocity loop. The comparison examines both performance and robustness to parameters' uncertainty. The design of the $\mathrm{H}_{\infty}$ controller is based on the concept of $\mathrm{H}_{\infty}$ loopshaping control.

The present paper is organized as follows: Section II describes the wind generator, its modelling and the corresponding control architecture. Section III summarizes the design of the current controller for the HESM generator quite quickly since it's a classic approach. Section IV is dedicated to the speed controller design. The two proposed methods are detailed. Section V gives simulation results and compares the two designs in terms of stability, performance and robustness to parameter variations. Finally, a conclusion and some prospects close the paper.

\section{Wind Generator Setup}

\section{A. Wind Generator Modelling}

Ref. [6] develops the modelling of the full system presented in Fig. 1, while Table 1 gives the definition, the nominal value and the variation range of the parameters used in this study.

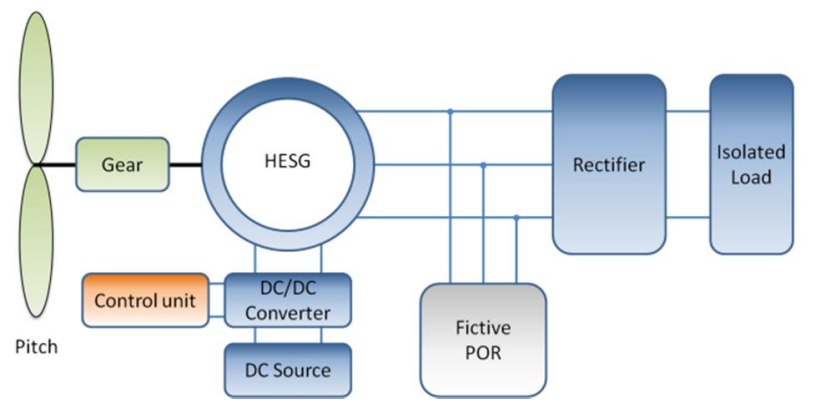

Fig. 1. Architecture of the studied wind generator

Table 1. Parameters names, values and variation ranges.

\begin{tabular}{|c|c|c|c|}
\hline $\begin{array}{l}\text { Parameter } \\
\text { (unit) }\end{array}$ & Name & $\begin{array}{l}\text { Nominal } \\
\text { Value }\end{array}$ & $\begin{array}{l}\text { Range } \\
(\%)\end{array}$ \\
\hline$\rho\left(\mathrm{Kg} / \mathrm{m}^{3}\right)$ & $\begin{array}{l}\text { Density of } \\
\text { air }\end{array}$ & 1.2 & \\
\hline$f_{t}\left(k g \cdot m^{2} s^{-1}\right)$ & Viscous gain & $10^{-3}$ & \\
\hline $\mathrm{J}_{\mathrm{t}}\left(\mathrm{Kg} \cdot \mathrm{m}^{2}\right)$ & Inertia & $5 \cdot 10^{-3}$ & \\
\hline $\mathrm{L}_{\mathrm{d}}(\mathrm{mH})$ & $\begin{array}{l}\text { d-axis } \\
\text { inductance }\end{array}$ & $\mathrm{L}_{\text {dnom }}=6.9$ & $50-100$ \\
\hline $\mathrm{L}_{\mathrm{q}}(\mathrm{mH})$ & $\begin{array}{l}\text { q-axis } \\
\text { inductance }\end{array}$ & $\mathrm{L}_{\text {qnom }}=8.9$ & $50-100$ \\
\hline $\mathrm{p}$ & $\begin{array}{l}\text { Number of } \\
\text { poles pairs }\end{array}$ & 6 & \\
\hline $\mathrm{L}_{\mathrm{e}}(\mathrm{mH})$ & $\begin{array}{l}\text { Excitation } \\
\text { inductance }\end{array}$ & $\mathrm{L}_{\text {enom }}=50$ & $50-100$ \\
\hline $\mathrm{G}_{0}$ & $\begin{array}{l}\mathrm{DC} / \mathrm{DC} \\
\text { converter } \\
\text { gain }\end{array}$ & 10 & \\
\hline $\mathrm{m}_{\mathrm{p}}$ & $\begin{array}{l}\text { Multiplier } \\
\text { coefficient }\end{array}$ & 5 & \\
\hline $\mathrm{R}_{\mathrm{p}}(\mathrm{m})$ & Pale radius & 3 & \\
\hline$\psi_{\mathrm{a}}(\mathrm{mWb})$ & $\begin{array}{l}\text { Excitation } \\
\text { flux }\end{array}$ & $\Psi_{\text {anom }}=66$ & $80-100$ \\
\hline $\mathrm{M}(\mathrm{mH})$ & $\begin{array}{l}\text { Mutual } \\
\text { inductance }\end{array}$ & $\mathrm{M}_{\text {nom }}=7.3$ & $80-100$ \\
\hline
\end{tabular}

\begin{tabular}{|l|l|l|l|}
\hline $\begin{array}{l}\text { Parameter } \\
\text { (unit) }\end{array}$ & Name & $\begin{array}{l}\text { Nominal } \\
\text { Value }\end{array}$ & $\begin{array}{l}\text { Range } \\
(\boldsymbol{\%})\end{array}$ \\
\hline $\mathrm{R}_{\mathrm{e}}(\Omega)$ & $\begin{array}{l}\text { Excitation } \\
\text { resistance }\end{array}$ & $\mathrm{R}_{\text {enom }}=1.35$ & $100-150$ \\
\hline $\mathrm{R}_{\mathrm{s}}(\Omega)$ & $\begin{array}{l}\text { Stator } \\
\text { resistance }\end{array}$ & $\mathrm{R}_{\text {snom }}=0.76$ & $100-150$ \\
\hline
\end{tabular}

\section{B. Control Architecture}

For a given value of wind, it is proven in [6] that a unique value of HESM rotation speed insuring the MPPT control exists. Thus, a classic cascade control scheme is adopted, with an inner current loop and an outer speed loop as shown in Fig. 7 and Fig. 8. In Fig. 8, $K_{\Omega}(s)$ is the velocity controller and $C L_{i}(s)$ is the excitation current's closedloop presented in Fig. 7. $K_{i}(s)$ is the excitation current's controller. $\Omega_{\text {ref }}$ is the velocity reference while the current reference $i_{\text {eref }}$ is the output of the controller $K_{\Omega}(s)$.

\section{Current Controller Design}

The excitation current's model was presented in [6]. It is shown in Fig. 7 and implemented in the Simulink environment. As seen from this figure, the excitation current model is a multi-input $\left(v_{e c}, v_{d}, i_{d}, i_{q}, \Omega\right)$ and strongly coupled nonlinear system. The usual technique is to compensate for the coupling term $v_{\text {pert }}$ defined by (1) with a feed-forward compensation but previous work [11] has shown that feed-forward compensation was not consistent with robustness to parametric uncertainty. Therefore, no compensation is used and (1) is neglected as a disturbance.

$$
v_{\text {pert }}=\frac{M \sqrt{3}}{L_{d}} \times\left(v_{d}-R_{s} i_{d}+L_{q} \omega i_{q}\right)
$$

The transfer function to control is then a first order so a simple PI controller is adequate. It is defined by (2) where $T_{i}$ compensates the excitation current's time constant $\tau_{\mathrm{i}}$ and $K_{i}$ is calculated to impose a control voltage $v_{e c}$ compatible with common level of control voltages. The excitation current's closed-loop is (3).

$$
\begin{aligned}
& K_{i}(s)=K_{i} \times\left(\frac{1+T_{i} s}{T_{i} s}\right) \\
& \text { with } T_{i}=\frac{\sigma L_{e}}{R_{e}}=\tau_{i}=0.02 \mathrm{sec} \\
& \text { and } K_{i}=0.4 \\
& \qquad \frac{i_{e}(s)}{i_{\text {eref }}(s)}=\frac{1}{1+\tau_{i B F} s}
\end{aligned}
$$

To test the current's loop, a step is imposed on $i_{\text {eref }}$ for different values of the electrical parameters $R_{e}, R_{s}, L_{e}, L_{d}$, $L_{q}, M, \Psi_{a}$ and $\sigma$ to simulate uncertainties on the model. As one can see on Fig. 2, the response of the current's closed-loop gives good results in all tested cases. One can conclude that stability and performance are robustly satisfied with a simple PI controller. Besides, this solution allows minimizing the number of sensors: only a current sensor for the excitation current is needed. 


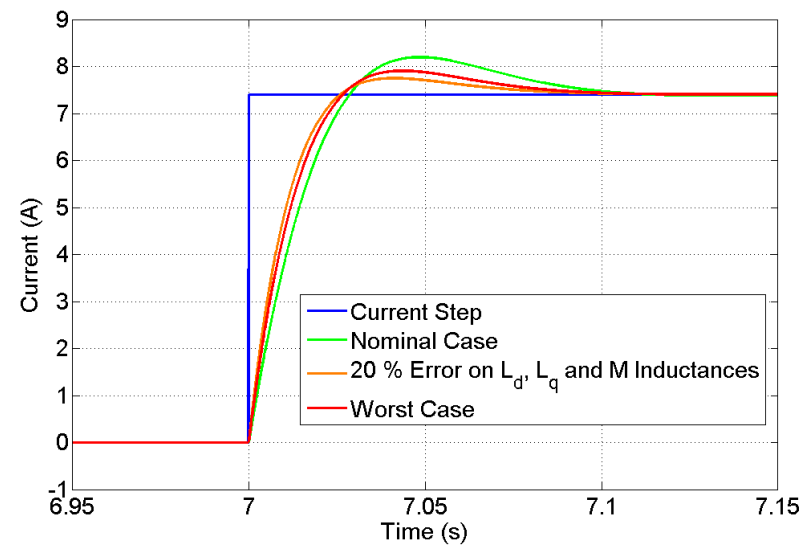

Fig. 2. Excitation current wrt to a step on $i_{\text {eref }}$ - Robustness's analysis with no feed-forward compensation.

\section{Velocity Controller Design}

The angular velocity's model was presented in [6]. Its block diagram is the one framed in blue in Fig. 8. The inner current loop must be at least ten times faster than the outer loop so the velocity controller must ensure a settling time around $500 \mathrm{~ms}$ for the velocity's closed-loop since the settling time for the current loop is about $50 \mathrm{~ms}$ (Fig. $2)$. With this choice the $C L_{i}(s)$ block in Fig. 8 can be omitted and $i_{e} \approx i_{\text {eref }}$.

\section{A. Adaptive PI Controller}

A simple PI controller is not sufficient to control the speed dynamic because the $i_{q}$ input induces a nonlinear coupling. However, if the gain of the PI controller is adaptive and depends on the $q$-axis armature current as shown in Fig. 8, the control is possible. To implement this solution, a feed forward compensation strategy is necessary and then adopted. The proposed controller architecture is given in Fig. 3 and the PI controller expression is defined in (4).

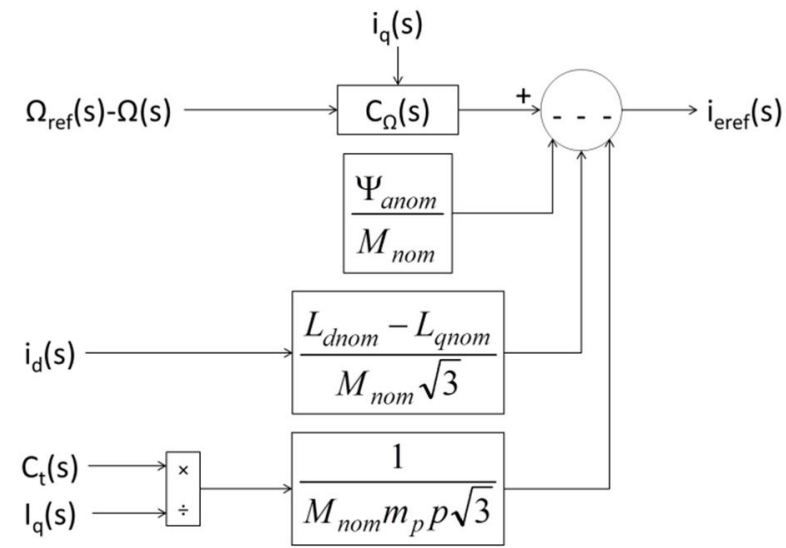

Fig. 3. Adaptive PI controller architecture with feed forward compensation.

$$
\begin{aligned}
& K_{\Omega}(s)=K_{\Omega}\left(i_{q}\right) \times\left(\frac{1+T_{\Omega} s}{T_{\Omega} s}\right) \\
& \text { with } T_{\Omega}=\frac{J_{t}}{f_{t}}=5 \mathrm{sec} \\
& \text { and } K_{\Omega}\left(i_{q}\right)=\frac{J_{t}}{T_{\Omega C L} M_{\text {nom }} \sqrt{3} p m_{p}^{2} i_{q}}
\end{aligned}
$$

$T_{\Omega C L}$ is the closed speed loop setting time $(500 \mathrm{~ms})$.

\section{B. Hळ Controller}

Regarding $\mathrm{H}_{\infty}$ control theory, there are mainly two approaches: a method based on closed loop specifications and a method based on open loop specifications. The first one is known as the standard $\mathrm{H}_{\infty}$ problem. The second method is known as the Normalized Coprime Factors (NCF) robust stabilization problem. Since this method does not address performance directly, it is usually connected with a loop shaping procedure. This latter method has been chosen because it relies on conventional concepts of automatic control to adjust the performance and so is easier to use. The problem was formulated and solved by D.C. Mc Farlane and K. Glover [12], [13] and Matlab routines are available to get the controller.

As seen from Fig. 8, the angular velocity's model is a multi-input $\left(\Psi_{\mathrm{a}}, C_{t}, i_{d}, i_{q}\right)$ and strongly nonlinear system. The $\Psi_{\mathrm{a}}, C_{t}$ and $i_{d}$ inputs can be considered as disturbances from the point of view of the control and then are not taken into account for the design of the velocity's controller. The $i_{q}$ input induces a nonlinear coupling between the excitation current and the $q$-axis current and can't be neglected. As the $\mathrm{H}_{\infty}$ loop-shaping design procedure requires a linear model, it is necessary to linearize the turbine dynamics. This work is described in [11] together with the choice of an average model for the controller synthesis. The transfer function is given in (5):

$$
\frac{\Omega(s)}{i_{\text {eref }}(s)}=\frac{4.222 \times 10^{4}}{\mathrm{~s}^{2}+24.3 \mathrm{~s}+729}=G(s) \quad\left(\operatorname{rad} \cdot \mathrm{s}^{-1} \cdot \mathrm{A}^{-1}\right)
$$

As said previously, to address the desired closed loop performance in a NCF robust stabilization problem, it is necessary to introduce compensators on the model to shape the Bode diagram of the augmented model. For a single-input, single-output model, only a precompensator $W_{1}(s)$ is required. So, the first step is to select a pre-compensator and adjust its parameters to ensure that the open loop has a high gain in low frequencies (to ensure a good reference tracking), a smooth frequency response, a $-20 \mathrm{~dB} /$ decade gradient around the desired closed loop bandwidth (to ensure a good phase margin) and a low gain in high frequencies (for a good noise and disturbances rejection). For the model (5) a PI compensator is a good choice. Indeed, an integral action is necessary to ensure a high gain in low frequencies since (5) does not have an integrator. Besides, the natural slope of (5) is $-40 \mathrm{~dB} /$ decade at high frequencies. This is enough to provide a satisfying rolloff. So no additional low-pass filter is needed. The integral action of the PI controller is stopped around the cut-off frequency of $G(s)$. The static gain is adjusted to obtain the desired bandwidth and thus the closed-loop's settling time. After tuning, $W_{1}(s)$ is:

$W_{1}(s)=K_{1} \times \frac{1+T_{1} s}{T_{1} s}=6 \times 10^{-3} \times \frac{1+0.03 s}{0.03 s}$

The augmented model $G_{a}(s)=G(s) W_{1}(s)$ has a satisfying Bode shape and a value of 0.63 is obtained for the 
maximum stability margin $\varepsilon_{\max }$ which is a good result for the robustness of the closed-loop. The $\mathrm{H}_{\infty}$ controller $K_{\infty}(s)$ is computed with the Matlab $n c f s y n$ function and the controller is obtained by combining $K_{\infty}(s)$ and $W_{1}(s)$ :

$$
\begin{aligned}
& K_{\Omega}(s)=W_{1}(s) K_{\infty}(s) \\
& K_{\Omega}(s)=\frac{0.443 s^{3}+25.47 s^{2}+651.5 s+9836}{s^{4}+99 s^{3}+4 \times 10^{3} s^{2}+7 \times 10^{4} s}
\end{aligned}
$$

Fig. 4 shows the Bode plot of the controlled open-loop. As predicted by the value of $\varepsilon_{\max }$, an excellent phase margin of 78 degrees is achieved.

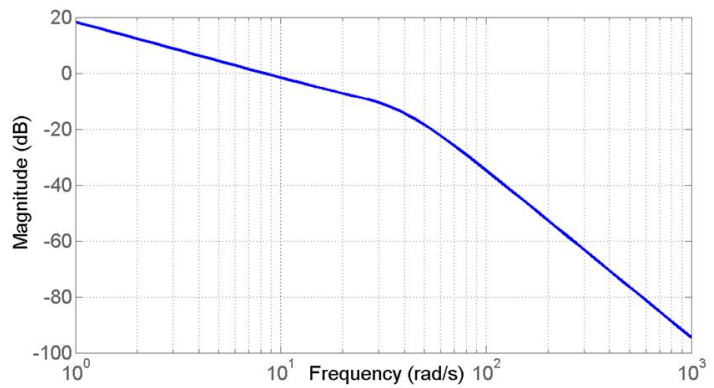

(a) Magnitude

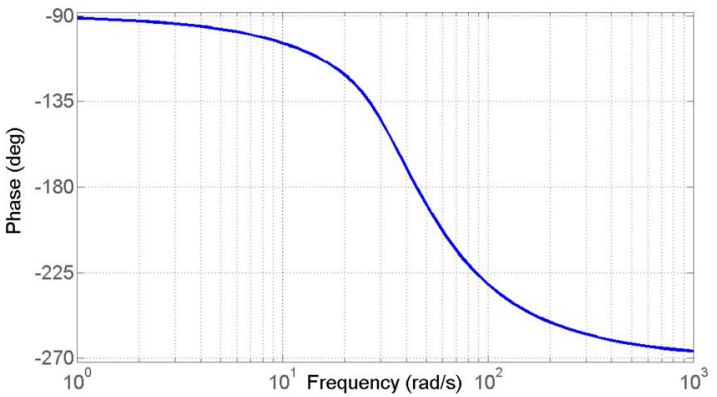

(b) Phase

Fig. 4. Bode Plots of the Controlled Open-Loop.

\section{Comparison of the Two Designs}

As noted in Section II, the electrical parameters of the HESG are very uncertain. It is therefore vital to check the robustness of the designed controls. The implementation of the two loops is shown in Fig. 7 and Fig. 8. In Fig. 8, $C L_{i}(s)$ is the excitation current's closed-loop of Fig. 7 and the velocity controller is (4) or (7). In Fig. 7, the excitation current's controller is the one presented in (2).

Simulations are conducted to evaluate the performance and robustness of the angular velocity's closed-loop. A step is imposed on $\Omega_{\text {ref. }}$. Parameters $R_{e}, R_{s}, L_{e}, L_{d}, L_{q}, M, \Psi_{a}$ and $\sigma$ vary to simulate uncertainties on the model while the controllers (2), (4) and (7) are the ones computed with the nominal values.

Simulations with the adaptive PI controller (4) are given in Fig. 5. It can be seen that only the nominal case gives a good result (green). If the feed forward compensation is removed, the angular velocity can't reach its reference (orange). As a matter of fact, with a variation of only one term of the feed forward compensation (for instance, the permanent magnet excitation flux $\psi_{\mathrm{a}}$ ), the velocity can't follow its reference (red). That is to say the robustness is not ensured with an adaptive PI controller.

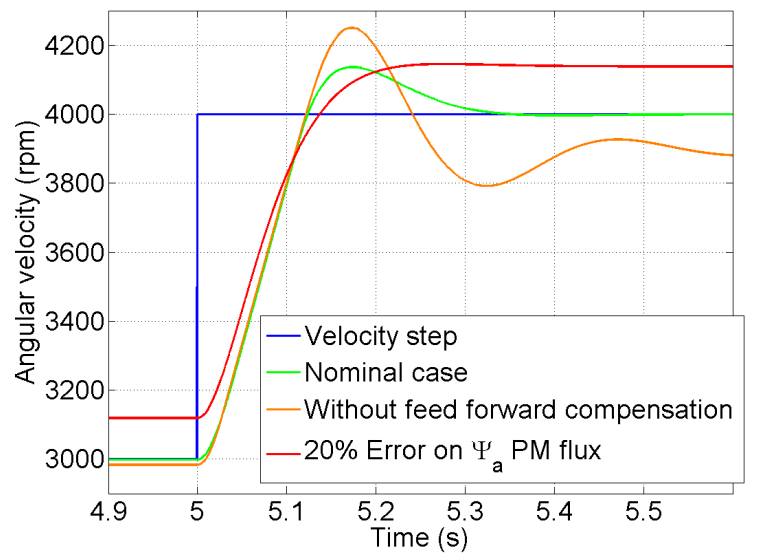

Fig. 5. Angular velocity's closed-loop at $\Omega_{\text {ref }} \approx 3000 \mathrm{rpm}$.

As one can see on Fig. 6, the response of the $\mathrm{H}_{\infty}$ velocity's controlled loop gives good results in all cases. Nominal case (red line: all the electrical parameters are at their nominal values as defined in Table 1) is the one with the maximum overshoot $(6 \%)$ and the maximum settling time $(0.32 \mathrm{sec})$. The worst case (magenta line) as defined when all the electrical parameters of the HESG are at the maximum of their uncertainty range - see Table 1) presents a satisfying behaviour so one can conclude from these simulations that stability and performance are robustly satisfied with the $\mathrm{H}_{\infty}$ controller.

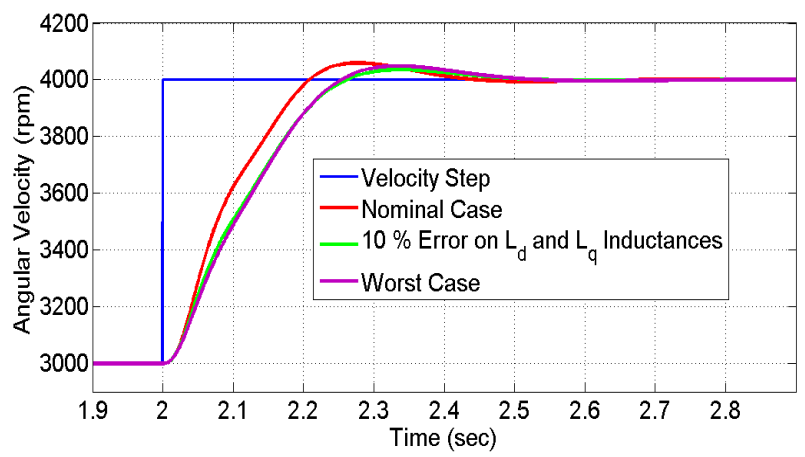

Fig. 6. Angular velocity's closed-loop at $\Omega_{\text {ref }} \approx 3000 \mathrm{rpm}$.

\section{Conclusion}

In this paper, a robust and low-cost structure for a generator connected to an isolated load for wind applications is introduced and a comparison between an adaptive PI controller and an $\mathrm{H}_{\infty}$ controller for the velocity loop is presented. The comparison examines both performance and robustness to parameters' uncertainty. After the description, the modelling and the corresponding control architecture of the wind generator, a brief section exposes the design of the HESM current controller which is classical. Two methods are then presented and detailed for the synthesis of the speed controller. The simulation results show that in terms of stability, performance and robustness to parameter variations, the $\mathrm{H}_{\infty}$ controller is very robust while the adaptive PI controller works only for the nominal case. Finally, the proposed $\mathrm{H}_{\infty}$ controller allows minimising 
the required number of sensors. A test bench is under construction to obtain experimental validation for the proposed generator.

\section{References}

[1] Ming Cheng, Ying Zhu, "The state of the art of wind energy conversion systems and technologies: A review", Energy Conversion and Management, Volume 88, December 2014, Pages 332-347.

[2] F. Belloni, R. Chiumeo, C. Gandolfi, A. Villa, "Simulation model of a Permanent Magnet Synchronous Generator for grid studies", International Conference on Renewable Energies and Power Quality (ICREPQ'14), ISSN 2172-038 X, No.12, April 2014.

[3] S. Fragoso, F. Vázquez, F. Morilla, "Practical Advantages of Multivariable Control Strategy for Off-Grid Variable-Speed Variable-Pitch (VS-VP) Wind Turbines", International Conference on Renewable Energies and Power Quality (ICREPQ'14), ISSN 2172-038 X, No.12, April 2014.

[4] F. Poitier, «Etude et commande de génératrices asynchrones pour l'utilisation de l'énergie éolienne », Thèse de Doctorat de l'Université de Nantes, 2005.

[5] A. F. Carneiro, M. D. Lucas and F. K. A. Lima, "Wind Turbines Based on Doubly Fed Induction Generator in Coordinate Operation with a STATCOM", International Conference on Renewable Energies and Power Quality (ICREPQ'14), ISSN 2172-038 X, No.12, April 2014.

[6] Berkoune K, Ben Sedrine E., Vido L, Le Ballois S., "Control and Operating Point Optimization of Hybrid Excitation Synchronous Generator applied for wind application", Electrimacs, I.S.B.N. 978-84-616-99612, Publication Year: 2014 , Page(s): 104- 111.
[7] N. Patin, L. Vido, E. Monmasson, J.P. Louis, M. Gabsi, M. Lecrivain, "Control of a hybrid excitation synchronous generator for aircraft applications", IEEE Transactions on Industrial Electronics (2008), 55 (10), pp.3772-3783.

[8] E. Ben Sedrine, L.Vido, I. Slama-Belkhodja, M. Gabsi. "Control of a Hybrid Excitation Synchronous Generator for a Wind Energy Application", 14th European Conference on Power Electronics and Applications (EPE'11), pp. 1-10, 2011.

[9] L. Vido, M. Gabsi, M. Lecrivain, Y. Amara, F. Chabot, "Homopolar and Bipolar Hybrid Excitation Synchronous Machines", in Proc. IEEE International Conference on Electric Machines and Drives, TX, USA, May 15-18, 2005.

[10] Y. Amara, K. Oujehani, E. Hoang, M. Gabsi, M. Lecrivain, A.H. Ben Ahmed, S. Derou. "Flux Weakening of Hybrid Synchronous Machines", in Proc. IEEE International Conference on Electric Machines and Drives, Cambridge, MA, USA, June 17-20, 2001.

[11] K. Berkoune, E. Ben Sedrine, L. Vido, S. Le Ballois, "Robust Control of Hybrid Excitation Synchronous Generator for Wind Applications, Submitted for publication in Mathematics and Computers in Simulation Journal, Elsevier (MatCom), October 2014.

[12] McFarlane, K. Glover, "Robust Controller Design Using Normalized Coprime Factor Plant Descriptions", Lecture Notes in Control and Information Sciences, Springer Verlag, 1990.

[13] McFarlane, K. Glover, "A Loop Shaping Design Procedure Using $\mathrm{H}_{\infty}$ Synthesis", IEEE Transactions on Automatic Control, AC-37, $\mathrm{n}^{\circ}$ 6, pp. 759-769, 1992.

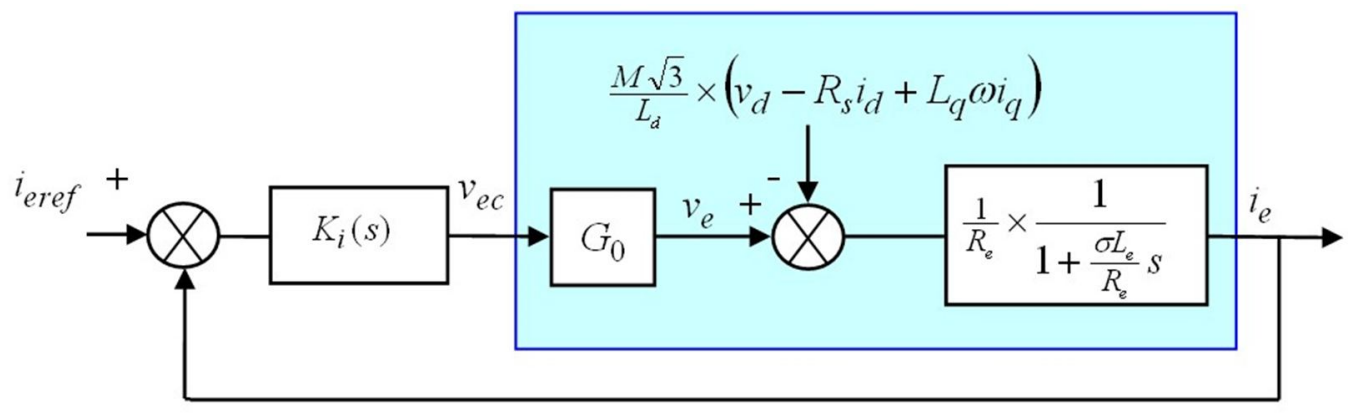

Fig. 7. Excitation current's closed-loop $C L_{i}(s)$. The excitation current's model is framed in blue.

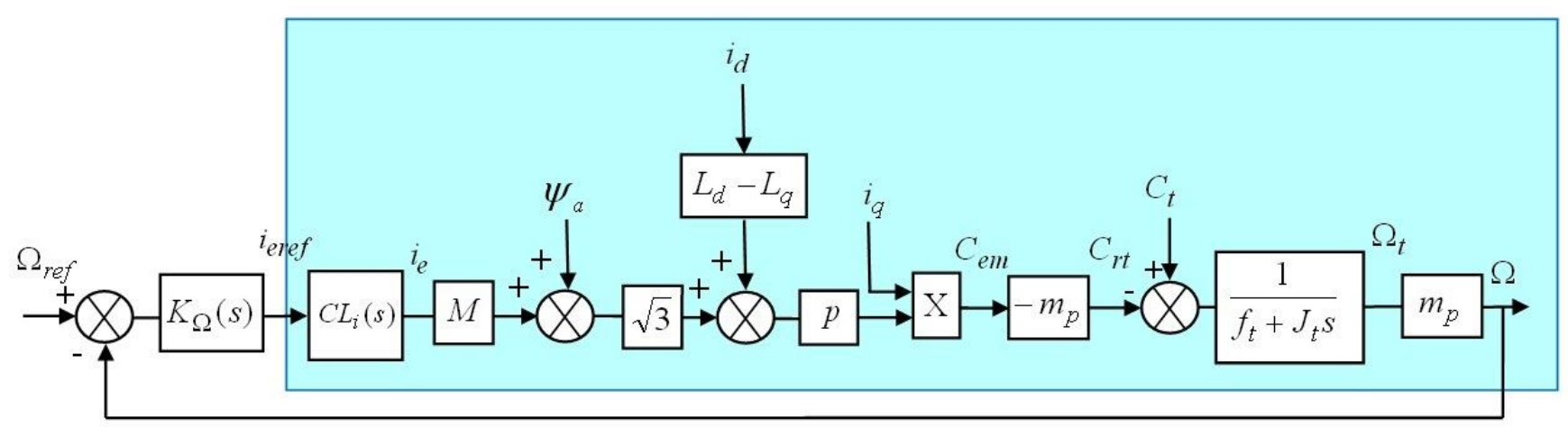

Fig. 8. Control Architecture. A cascade control scheme is adopted with $C L_{i}(s)$ the excitation current's closed-loop. 